\title{
Electrical Conditions of the Earth and Atmosphere
}

\author{
Their Influence Upon Animate Nature
}

\author{
By A. E. Baines
}

Although the subject of electrical conditions of the earth and atmosphere and their influence upon animate nature is one of widespread interest and importance, $I$ have not been able to find any literaimportance, I have not been able to find any literature dealing with it and am therefore encouraged of the general public.

A few months ago I pointed out to the eminen English scientist, Dr. Russell, that in his admirable work, Soil Conditions and Plant Growth (Longmans) he had omitted all consideration of electrical phe nomena. In his replay he said, "We have not gon into this question of electrical conditions, because into this question of electrical condition

Evidence there is, in plenty. That it has not bee published is a matter for regret. Now that attention is being directed to electro-culture it is ver necessary to have some understanding of the part played by Nature, and of her methods before we seek to improve upon them. Experimentation with out a starting point, a definitely ascertained basis of fact very seldom results in success, and in this

of fact very seldom results i
case the basis is not wanting.

In countries free from frequent magnetic an seismic disturbances and in normal conditions of weather the earth is always the negative and the air the positive terminal of Nature's electrical sys tem.

The air is not only charged by some source or sources of energy in the Solar System, or at at events above the air limit, but is from time to tim the carrier of currents of high potential from clouds which acquire a static charge in the course of their movements.

The earth, therefore, is perpetually in process of electrification, an: its receptivity is dependent for it degree upon the conductivity of its upper stratum. Dry soil is a non-conductor, or at all events a very bad conductor of electricity, and uniformity of ele trification could only be possible if the resistance of the upper stratum of the soil were everywhere the same. To thit question we will, however, retur later.

Everything growing in the soil is charged-electrified-by the earth through the roots, rhizomes, stems and venation; the negative terminals of the tree, shrub or plant. The aerolae, or those part of the leaves between the venation, take their charge from the positive air, so that there is in every cas an ordinary electrical current, i.e., air to earth and back again through the plant to air.

That, however, does not exhaust the phenomena we are about to pass in review. Earth-curren proper are set up both occasionally and frequently in different parts of the world by chemical rea tions taking place in the earth itself and, furthe more, modernity has, in some of the large town introduced a new factor in a multiplicity of electrica railways, tubes and tramway systems; and this fac theory that, as compared with all other electrical theory that, as compared

In certain localities and in abnormal weather in other localities, the earth may become very highly charged. The terms "positive" and "negative" are misnomers. Let us substitute for them the word "plus" and "minus."

The air, the upper stratum and, hypothetically, stretch ing upwards to infinity, is always "plus," the earth, usually, "minus."

Between a charged cloud and the comparatively ncharged earth there is an air-space-the spar gap, as it were-and unless the tension of the clou is suffic ently high to bridge it no discharge can take place. Over a flat surface of ground or above a surface either very dry or composed of some dielectric material, such as shale or marl, the the cloud would pass without discharging, but when by reason of contour the $d$ 'stance between earth by reason of contour the distance between earth
and cloud was lessened to one that the tension of the cloud could overcome, or, alternatively, tensio be'ng enough, a point was reached where the so eavored conduction, a transfer of potential from the plus cloud to the minus earth would at once take place, in exactly the same manner that a spark is obtained from a Leyden far or fnduction coil when the conducting knobs or points are approached to ach other.

Ordinarily such a discharge would, when received e diffused over a wide area of ground, but let us uppose that it is directed to a pocket of earth in a basin of shale, or clay, or marl, or stone so that it could not be readily dissipated and that an other cloud which had already discharged itsel passed over the position within a distance over which the spark gap could be bridged. The result would be a discharge from earth to cloud, because the earth would have become the plus and the cloud the minus quantity.

The Natural electromotive force of man-so far as it can be expressed in electrical terms-is about five millivolts, or five thousandths of a volt. He is almost as receptive of direct or induced charge as the earth is, and any sudden and violent interference with that electromotive force by an external source or vehicle of energy would temporarily have a mis chievous effect upon his nervous system.

That is a danger to whieh we are not ordinarily exposed, but to a modified extent we may regard the electrical phenomena consequent upon the opration of an electric railway as analagous to that we have been discussing, leading for electrified clouds the effect upon the air of alteration or load, while the iron-clad tubes, with their far from perfect in sulation, must be responsible for artificial earth-curents of considerable intensity.

Similarly, in tramway lines where direct current is employed the overhead system is likely to affect the air locally, and the conduit system to charge the earth, although the range of inductive interference is not nearly so great as in the case of electrified ailways and tubes.

Quite apart from thunderstorms and kindred disturbances, the earth is electrically "patchy"; the potential and direction of current varying in different parts of the world. The mean of a series of tests taken at the instance of one of the great cable companies gave eight volts as the E.M.F. of the earth-current traversing short cables, but I am credibly informed that at Port Arthur it has sometimes risen to 500 volts.

Darwin found the neighborhood of the Rio Plata to be peculiarly subject to electrical phenomena and on the East African coast the earth-current has remained at forty volts for many weeks in succession.

Flammarion attributed the Aurora Borealis to the striking of a balance, silent and invisible, setween the two opposing tensions of the atmosphere and earth; the apparition of the Aurora Borealis in Swe den or Norway being accompanied by electric cur rents moving through the earth to a distance sufficiently great to deflect the magnetic needle in the Paris Observatory.

The same writer expressed the opinion that the electricity which pervades the earth is identical with that which moves in the heights of the enveloping atmosphere, and that whether it is positive or negative its essential unity remains the same, these qual Ities serving only to indicate a point, more or less in common, between the different charges. The heights of the atmosphere are more powerfully electrified than the surface of the globe, and the degree of electricity increases in the atmosphere with the distance from the earth.

That indeed must be so, in conformity with Ohms law, i.e., $\mathbf{C}=\frac{\mathbf{E}}{\mathbf{R}}$ if we assume, as we must, I think, assume the source of electrification of the atmosphere to be above the air limit, because resistance attenuates electrical energy in proportion to th distance traversed by it, i.e., through the envelopin atmosphere; the equation $\mathbf{C}=\frac{\mathbf{E}}{\mathbf{R}}$ meaning that the current at any point is equal to the initial electromotive force divided by the total resistance in its path to that point.

That earth currents have at times an origin whic is in part thermal seems not unlikely. Earthquakes are of common ocearrence in the tropies and elsewhere. Dutton records an instance of an earth quake at the Yaqui river which disturbed the needle of the magnetograph at Los Angeles, a distance of more than six hundred miles, and it is possible that erces which in themselves are insufficient to caus even a slight convulsion of Nature may be respon sible for the creation of high potential at one point whence it is distributed to another point or points of lower potential; the precise path being governed by electrolytes in the earth, or, in other words, by the same law which directs the course of lightning through the atmosphere.

In speaking of earthquakes we must, of course differentiate between those which are caused by sub. sidences and those of volcanic origin. Volcanoes are not confined to any one part of the world, but are to be found, so far as latitude is concerned, pretty nearly everywhere; in the Arctic Ocean, in the volcanic island of Jan Mayen, between Iceland and Spitsbergen; there are Mount Erebus and Mount Terror in the Antarctic, besides very numerous volcanoes in the Atlantic, Pacific, and Indian Oceans, and their shores, in both the temperate and torrid zones. In all they are said to

activity, some three hundred.

But, as Houston writes, "There are a much greater number of extinct (?) volcanoes, volcanoes which may at any time again become active."

The difficulty we are faced with is contained in the last paragraph. Were it not for the uncertain number and condition of extinct volcanoes, or rather of volcanoes which have ceased for the time being to give any manifestation of activity, we might consider earth-currents in their possible relation to areas liable to thermal disturbances with a view to determining whether connection between them is suggested by their coincidence.

One fact stands out prominently: thunderstorms diminish in frequency towards the poles, and if they are a factor in governing the occurrence and strength of earth-currents one would expect to find a minimum of disturbance towards the poles. That does not, however, appeear to be the case, as currents of very high tension are met with in the far north.

As regards plant-life, the electrical condition most to be desired is soil conductivity. If the soil is not moist to the root-depth, or, alternatitvely, if it does not contain electrolytes other than water, the plant is deprived of its supply of current and must suffer injury.

If, however, about one per cent. of ferro sulphate, or another suitable electrolyte, is mixed with the soil or the gromnd is well watered with that mineral in solution, a great deal of the water ordinarily required may be dispensed with; the ferro sulphate taking its place as the electrolyte.

I have potted plants in baked soil with which a solution of one per cent. of the iron salt has been mixed-and then expelled-and have kept them alive in a warm greenhouse, exposed to the sun's rays, for three months without water. They did not grow, because there was no moisture for the formation of protoplasm-but they lived when the soil in the pot was electrified by means of a continuous current of low electromotive force; not when this was omitted.

Normally the moist earth in the pot is receptive of charge from the positive air and although this involves reversal of polarity on the part of the plant it manages to thrive. With dry soil, however, there is total absence of electrification; the plant becomes moribund and eventually dies.

Not only is it necessary that the soil should be conductive, but we have to take into account the factor of its resistance because this would govern the quantity of current reaching the plant-roots. If every part of the earth were of exactly the same resistance all things growing in it wor. $t$ be uniformly electrified, but we may be quite sure that electrolytes are neither equally distributed throughout the soil, nor of uniform resistance, so that elecrification cannot be everywhere the same.

When a "fault," such as a pocket of earth in a pocket is fust as dependent upon air charge as the Doil in a pot would be and in dre weather, with noll in a pot would b non-conducting upper stratum it would become olec-
trioally inert. Remedjal measw' вs or attempted 
remedial measures now employed take the form of breaking up the underlying dielectric, but this is only practicable when the material in question is not far from the surface.

A more simple way out of the difficulty would be to drive a metal rod or tube through the dielectric and enable the earth-current to pass through or by it from below.

Theoretically it is desirable to test soils for cur rect and where there appears to be a deficiency to arrange for a constant supply, at a voltage not ma terially higher than that which normally obtains.

Furthermore we have the important matter of temperature in its relation to electrical conditions of the soil. In warm, damp weather conductivity is at its maximum. Cold increases resistance-espe c:ally of liqu:d conductors-and lowers the quantity of current supply. There is in fact not only dimin ished supply to the roots, but in very cold season what one might term protoplasmic paralysis, a condition which in the case of perennials merely in hibits growth, but which is generally fatal to species of the tender or half-hardy order.

When vegetable life is said to be "resting" during the late autumn and winter months it is (in my opinion) probably due to lowered electrification.

Man is liable to be affected in much the same way and we may be sure that lowered vitality not only predisposes to disease, but operates against its cure. In the polar regions larger temperature ranges can be endured in the winter, when the air is dry. In severe cold the vitality of the body is lowered and the ability to bear hardships decreased. But here, again, the body is acted upon directly by cold. The resistance of the natural (semi-liquid) conduc tors is increased, the blood circulates more slowly, the surface blood-vessels contract, and only an added skin-resistance, by helping to conserve energy, and it may be, greater purity of air stimulating generation of nerve-force, prevent the heart and lungs from becoming dangerously affected. Esquimos are protected from the cold by their fatty tissues, which give them high absolute insulation; and those fregive them high absolute insulation; and those fre-
quenters of icy seas, the whales, are similarly equipped

Any abnormal skin condition, no matter how produced, must, in my view, interfere to a greater or lesser extent with metabolism. If the skin is dry its insulating properties are at their maximum. Exopposite effect and would at the same time lower the resistance of the nerve-substance, so that an increased quantity of current, and a path of greater facility for that current to escape to air, would be facility for that current to escape to air, would be
the result; bringing about a temporary loss of vitality. the result; bringing about a temporary loss of vitality.
The same remarks apply to exposure for long periods to damp air, except that the nerves would not be directly interfered with.

What I wish to labor is t:is: the human organism is provided-as an apple is provided-with a skin, or rind, the resistance of which is adjusted by $\mathrm{Na}$ ture for the conservation of his energy, and so long as normal conditions prevail that resistance is exactly right. If the skin is wet its resistance is subactly right. If the skin is wet its resistance is sub-
normal-if it is too dry the nervous system is liable normal-if it is too dry the nervous system
to become neuro-electrically congested.

In this connection I am glad to find that at least one physiologist of eminence-Dr. Leonard Hill-is in agreement with me, although our interpretation of observed phenomena may not be the same. He has produced maps showing that the energetic races of the world inhabit just those regions where atmosthe world inhabit just those regions where
pheric coolness and drying are most potent.

Many are familiar with the unpleasant symptoms attendant upon an abuse of sea bathing. They are, of course, due to the failure, during immersion, of the resistance of the skin and it is for this reason that long-distance swimmers anoint themselves with grease. Could they insulate the mouth and eyes in the same way they would, no doubt, be able to re main in the water for longer periods.

That the atmosphere is electro-magnetically active has been postulated by Clerk Maxwell and others, and we have it upon their authority, as well as upon that of Sir Oliver Lodge, that light is an electromagnetic disturbance of 'the ether. Optics is a lution of a potential of increasing intensity as progress is made from the red to the violet end of the ress is made from the red to the violet end of the
spectrum. Plant growth, as shown by experiment, is at its best in a red light and the rays of long wave-length, red and infra-red, are the only ones which Nature permits to penetrate the human body.
My readers will also be aware of the injurious effect of actiuic light and particularly of sunlight, upon cuttings and germinating seeds and have seen the

\section{necessity of protecting them from what is really
form of energy too violent for their constitution.} Hypothetically the electrification of the atmos phere should be higher in dry than in wet weather by reason of there not being a path of low resistance to earth; but a long series of test

On perfectly dry, warm days, with bright sunshine, the average deflection of an unshunted and very sensitive galvanometer ranged from 5 millimetres in the early morning to 2.5 millimetres at night. When it was wet-more especially with a steady, dazzling downpour, the deflections rose to 150 and not infrequently to 180 millimetres. Moreover, th initial throw disclosed a statie charge, the tensio of which was governed by that of the cloud or cloud discharging the rain.

Now if a vegetable or a fruit, such as an onion or an apple, be earthed in vacuo and its electrical
charge exhausted, it ceases for the time being to yield a galvanometric deflection. Afterwards, if exposed to the air the period necessary for the restoration of its former electrical activity is dependent upon quality of the light to which it is subjected. In a dull diffused light recovery is very prolonoted but in bright sunlight half an hour is sufficient.

But-and there is a perplexing feature-the form of energy exhibited by sunlight cannot be demon strated galvanometrically, unless it is transforme into heat, and then it is no longer a manifestation of sun-energy, but of another force which it has as sisted to bring into operation.

\section{Concerning Age.}

At what time does age begin? Hippocrates puts the period at the beginning of the seventieth year, while ccording to Vario, the Roman citizen was retired from all public offices at sixty (Senes depontani). In Solon' elegy upon the hebdomads of human life the greates development of bodily strength was attributed to the twentieth year. Aristotle placed the zenith of life at from thirty to thirty five, ordinarily, but declared that it continued to the forty-ninth year in men engaged in intellectual pursuits, saying that previous to and after this stage of life there existed a "too much" and "too little," hyperbole and ellipsis, expectation and experience. This subject, of such universal and poignant ence. This subject, of such universal and poignant
interest, of the coming of age, of its phenomena and interest, of the coming of age, of its phenomena and the subject of an interesting discourse pronounced b a German scientist, Friedrich von Mueller, at a celebration of the founding of the University of Munich, in June, 1915, a report of which we find in Die Natursis senschaften, part of which we quote as follows:

"Even with regard to the body alone all efforts to discover the boundary line of the beginning of age have remained without success. The various organs and functions undergo alteration at very various times and Friedmann is right when he says that the involution of evolution is so closely connected with its completion that decay has already begun in the period of youth. Thus the lymphatic system, the tonsils, the lymphatic gland and the thymus began to suffer atrophy soon as the development of the sexual organs is complete. The uteras and the secondary sex characters undergo atrophy when the true ovaries have begun their activity.

"Characteristic signs of age are the eyesight of old persons, the decline of the memory and of the muscular powers and the stiffness of the limbs: rigor signum senectutis (stiffness is a sign of age). Athletes dis play no remarkable feats of strength after thirty-flve years of age and reach the maximum of their muscula power before the thirtieth year. Among the workme of the English cutlery and button industries the amount of work done, as compared with that of younger men sinks to 80 per cent between the ages of forty and forty-five, to 60 per cent at the fifty-fifth year, and to 40 per cent at the age of sixty-five.

"The exesight begins to exhibit a change at about fifty; however, the elasticity of the lens begins to de
crease after the first decade of life and usually sink to zero at about the age of seventy-five.

"The power of observation is so great in youth that 70 per cent of all intellectual acquirements are obtained during this period, while difficulties appear afte the age of thirty. Since with increasing age the power of receiving new impressions and making them effective diminishes, there is a narrowing in the boundarie of the intellectual domain; an aged person is ofte indifferent or even hostile to modern ideas, he has decreased comprehension of the interests of youth and of its right to manage matters differently from the way they were done in the time of his own youth. With the increasing poverty of recent intellectual gains the firmly fixed memories of his youth gain in intensity and there is some justice in the view that the beginning of age dates from the time when the intellectual vision ceases to be directed towards the future and is bent upon the past. Earnest and serious thoughts engage the mind more and more; he who was formerly a seeker for truth becomes a doubter, the freethinker becomes a believer, the revolutionary a conservative. The greater the decrease in the power of adaptation the greater the power of habit becomes. The emotional life shrinks more and more to the narrow circle of the personal ego and its most immediate needs increasing susceptibility to fatigue and the consciousness of failing powers are painfully felt and produce a sensation of oppression or a certain amount of restlessness. It is also true that unadmitted doubts as to one's own worth often cause a correspondingly strong need of recognition from others, and this is expressed in various external ways which are quite incomprehensible to youth-as incomprehensible as miserliness, and the overvaluation of property, faults of age which writers and poets of all ages have scoffed at. Such descriptions of the senes marosi, ansii, difficiles, ira. qundi, avari.

Of the mournful decay which the psychiatrists have portrayed for us and which passes without any sharply defined dividing line into the domain of senile deimentia and the psychosis of age form a painful contrast to the serene image of the ienis placida fortis senectus which we find in the words and the example of a Goethe or a Jacob Grimm. 'It seems to be the case,' says Grimm, 'that old men take on a certain degree of acidity like old wine, yet we must remember that not every wine gets sour as it gets old' and he continues 'why should the old man do a less amount of work? His storehouses are filled and year by year he has added to their treasures through experience. Ought he to allow his hoarded treasures to fall into strange hands? In gifted and exceptional men strength and endurance long continue almost without any deterioration. To the unabated capacity for work and the undimmed eagerness for research there is added likewise another and a greater advantage, that consciousness of freedom which grows and strengthens with age; when the seeds of freedom have early been planted in a man's heart, when the noble plant that springs therefrom has flourished throughout a long life, how can it but be deeply rooted in the heart of the old man and bear him com pany to the end?' It is capable of proof, indeed, that the capacity for the production of original ideas develops later and disappears much later than the capacity for assimilating the ideas of others and above all the power of judgment is usually retained unaltered even amidst the intellectual contraction of the horizons of age, and this power of judgment supported by the experience of a long life and less liable to influence by emotion and passion than in youth and, therefore more just, is what lends its significance to age, making it the proper advisor of creative youth, especially in the domain of public life.

"Miehlmann and Ribbert have shown that the physiological death of old age starts with the brain. But this slow extinction of life in consequence of the failing of the functions of the brain is, in fact, a rare exception, since in nearly all cases some disease brings the life of the old person to an end. Hence, the problem of age, so far as the physician is concerned resolves itself into the diseases of age.

Diseases, whether through infection or traumatism, or through endogenous injuries, are particularly dangerous for old persons because of the lessened resistance of the organism.

Among other diseases of age we must include arte rial sclerosis and cancer, although both appear in younger life, and although it is quite certain that they are not conditioned by age alone. The problem of cancer is one of the obscurest in the science of pathology, as well as one of the most difficult in the art of healing . . . Areteriosclerosis seldom fails to make its appearance in old persons, and it is especially in the circles of men burdened with heavy duties that it seeks its victims. The previous history of the man wreaks its vengeance upon the blood vessels and the heart; every excess of emotion, of work or pleasure, of sorrow and anxiety, leaves its mark upon the arteries. These alterations silently increase in intensity through long years and are first made visible by the failure of the compensation apparatus to function. Thus arteriosclercsis is of $t$ n the final stage of a proces 3 which had already begun in youth."

The address closes with a brief survey as to the and races of men, of peoples and of empires. 